\title{
Probiotics in the prophylaxis of COVID-19: something is better than nothing
}

\author{
Kushal Gohil ${ }^{1,2} \cdot$ Rachel Samson $^{1,2} \cdot$ Syed Dastager ${ }^{1,2} \cdot$ Mahesh Dharne $^{1,2}$ (i)
}

Received: 11 July 2020 / Accepted: 12 November 2020 / Published online: 26 November 2020

(c) King Abdulaziz City for Science and Technology 2020

\begin{abstract}
The new viral pandemic of COVID-19 is caused by a novel coronavirus (SARS-CoV-2) that has brought the world at another unprecedented crisis in terms of health and economy. The lack of specific therapeutics necessitates other strategies to prevent the spread of infection caused by this previously unknown viral etiological agent. Recent pieces of evidence have shown an association between COVID-19 disease and intestinal dysbiosis. Probiotics comprise living microbes that upon oral administration benefit human health by reshaping the composition of gut microbiota. The close kinship of the gastrointestinal and respiratory tract suggests why the dysfunction of one may incite illness in others. The emerging studies suggest the capability of probiotics to regulate immune responses in the respiratory system. The efficacy of probiotics has been studied previously on several respiratory tract viral infections. Therefore, the purpose of this review is to comprehend existing information on the gut mediated-pulmonary immunity conferred by probiotic bacteria, in the course of respiratory virus infections and administration as a prophylactic measure in COVID-19 pandemic in managing intestinal dysbiosis as well.
\end{abstract}

Keywords Probiotics · Gut-lung axis · Anti-viral · COVID-19 $\cdot$ Respiratory tract infection

\section{Introduction}

Acute respiratory tract infections (pneumonia, influenza, enterovirus, adenovirus, and respiratory syncytial virus infections) accounts for one of the major causes of death and debility worldwide (Soriano et al. 2020). A majority of these infections are caused by DNA/RNA viruses. Infections associated with RNA viruses are notable than those caused by DNA viruses (Zolnikova et al. 2018). Coronaviruses, in particular, represent a highly important emerging RNA virus family causing respiratory infections (Su et al. 2016). The recent 'Coronavirus disease 2019' (COVID-19) pandemic causes Severe Acute Respiratory Syndrome (SARS). Some patients with COVID-19 showed a striking dysbiosis in the

Kushal Gohil and Rachel Samson contributed equally.

Mahesh Dharne

ms.dharne@ncl.res.in

1 Academy of Scientific and Innovative Research (AcSIR), Ghaziabad, India

2 National Collection of Industrial Microorganisms (NCIM), CSIR-National Chemical Laboratory, Pune, Maharashtra 411008, India probiotic group of intestinal microbes such as Lactobacillus and Bifidobacterium (Xu et al. 2020). In addition, some reports have confirmed a relationship between gut microbiota, secondary gut infection, and COVID-19 disease (Gu et al. 2020; Yeo et al. 2020; Gao et al. 2020). Furthermore, some reports have shown the presence of RNA of SARS$\mathrm{CoV}-2$ in fecal samples of some infected patients that tested negative for the presence of SARS-CoV-2 RNA in their respiratory samples (Wu et al. 2020; Xiao et al. 2020; Kopel et al. 2020). These shreds of evidence suggest crosstalk between the gut-lung axis, which to some extent may be modulated by probiotics, by favorably altering the gastrointestinal symptoms and shielding the respiratory system (Gu et al. 2020; Bottari et al. 2020). Therefore, this review article emphasizes to provide insights into the possible role of probiotics in COVID-19 prevention, in so doing, providing a starting point for future studies on it. Using keywords like COVID-19; SARS-CoV-2; probiotics in the respiratory tract infection; probiotics and antiviral activity; gut-lung axis; probiotics and coronavirus, we have derived the articles and reviewed for this review article. 


\section{Viral respiratory infections}

One of the major cause of worldwide mortality is acute viral respiratory infections (Fonkwo 2008). The most important viral pathogens in this front consist of rhinovirus, adenovirus, influenza virus, respiratory syncytial virus (RSV), and coronavirus. The clinical manifestations of these viruses range from mild symptoms to severe infection in the upper, middle, and lower respiratory tract (Lysholm et al. 2012). Adenovirus and rhinovirus have lower mortality but they are related to substantial morbidity (Pfeiffer and Virgin 2016). There is an annual increase in the global mortality rate as a result of influenza and RSV infection (Sahadulla 2018). The clinical manifestation upon infection with these respiratory viruses include common cold, bronchiolitis, croup, and pneumonia (Lehtoranta et al. 2014). Different viruses responsible for these clinical manifestations are enlisted in Table 1. Prevention of these infections poses a major challenge, since the available antivirals and vaccines for treatment are limited to influenza viruses and adenoviruses (Lee et al. 2018). Besides, a highly pathogenic group of viruses called coronaviruses cause a broad spectrum of respiratory tract infections (Zhang et al. 2020b).

\section{Coronaviruses and the COVID-19 disease}

Coronaviruses (CoV) are enveloped and highly diverse RNA viruses comprising of a large (25-32 kb), single-stranded, positive-sense RNA genome (Zhu et al. 2020). There are four subfamilies of coronavirus, namely alpha-; beta-(originating mainly from mammals, particularly from bats); gamma- and delta-(originating from pigs and birds) (Zhang and Holmes 2020). The alpha and beta-coronaviruses are known to cross animal-human barriers and cause severe disease and fatalities (Coleman and Frieman 2014). These coronaviruses can infect humans and as well as several other vertebrates and cause respiratory, enteric, hepatic, and neurologic diseases (Jiang et al. 2020). So far, six species of human coronaviruses have been identified. Among them, SARS-CoV and the Middle East Respiratory Syndrome Coronavirus (MERS$\mathrm{CoV}$ ) both having a zoonotic origin, can cause severe respiratory illness with high mortality (Fehr et al. 2017). Earlier in 2002-2003, the SARS-CoV virus emerged in China with an outbreak of severe acute respiratory syndrome (SARS) across 37 countries with $10.87 \%$ of causalities (Zhai et al. 2005). Later in 2012, another respiratory infection-Middle East respiratory syndrome (MERS), caused by MERS$\mathrm{CoV}$ emerged with more than $30 \%$ mortality in the Middle East countries (Luo and Gao 2020). To date, three highly pathogenic and lethal coronaviruses that infect humans are SARS-CoV, MERS-CoV and the recently reported one is SARS-CoV-2 (Meo et al. 2020).

In December 2019, a new type of Coronavirus, causing a cluster of pneumonia cases and deaths, emerged in the city of Wuhan, China, and spread out to other countries in the world rapidly, to become the current pandemic outbreak. The etiological agent behind the current pandemic of COVID19 is Severe Acute Respiratory Syndrome Coronavirus-2 (SARS-CoV-2) (Zhou et al. 2020). The isolated SARS-CoV-2 viral genome showed $88 \%$ and $50 \%$ genetic homology with
Table 1 Causes of common viral respiratory syndromes

\begin{tabular}{lll}
\hline Syndrome & Frequent causative agent (s) & Less common causative agents \\
\hline Bronchiolitis & RSV & Influenza viruses \\
& & Parainfluenza viruses \\
Adenoviruses & Rhinoviruses \\
Common cold & Rhinoviruses & Influenza viruses \\
& Coronaviruses & Parainfluenza viruses \\
& & Enteroviruses \\
& & Adenoviruses \\
Croup & & Human metapneumoviruses \\
Influenza-like illness & Parainfluenza viruses & RSV \\
Pneumonia & Influenza viruses & Influenza viruses \\
& & RSV \\
& Influenza viruses & Parainfluenza viruses \\
& RSV & Adenoviruses \\
& Adenoviruses & Parainfluenza viruses \\
& & Enteroviruses \\
& & Rhinoviruses \\
\hline
\end{tabular}

The table represent different types viruses responsible for respiratory syndromes $R S V$ respiratory syncytial virus

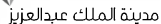
KACST 
SARS-CoV and MERS-CoV, respectively (Park et al. 2020). Hence, based on the genetic identity, the International Virus Classification Commission renamed the novel coronavirus-19 as SARS-CoV-2. It is an enveloped virus, having a positivesense, single-stranded RNA [(+) ssRNA] genome of $\sim 30 \mathrm{~kb}$. SARS-CoV-2 belongs to the order Nidovirales, family Coronaviridae, subfamily Coronavirinae, and genus betacoronavirus ( $\mathrm{Li}$ et al. 2020). As of 24th October 2020, there are over 42 million cases, with more than one million deaths worldwide (https://www.worldometers.info/coronavirus). SARS-CoV-2 is the seventh known species of coronaviruses responsible for the COVID-19 disease, characterized by acute pathological outcomes, including pneumonia and acute respiratory distress syndrome (ARDS) (Velavan and Meyer 2020). In addition, this virus can also cause severe infections resulting in septic shock, acute respiratory distress syndrome, acute cardiac injury, acute kidney injury, and multi-organ failure, which necessitate intensive care unit admission. Extremely severe cases of COVID-19 can lead to death (Guan et al. 2020). Presently, with the SARS$\mathrm{CoV}-2$ virus, the mortality rate is not as high as MERS, but the infectious rate of SARS-CoV-2 has challenged the specific development of therapeutics against COVID-19 disease (Seo et al. 2020). The temporary precautionary measures include hand-washing, use of masks, gloves, and isolation (Singhal 2020). Several efforts to develop vaccines against COVID-19 are underway, but the WHO estimates it will take 18 months for the COVID-19 vaccines to be available (Man Yi 2020).

SARS-CoV-2 is mainly transmitted via respiratory droplets from the infected persons, contact with surfaces contaminated by the virus, and through the eyes. The peculiar respiratory symptoms of SARS-CoV-2 include fever, cough, and severe respiratory syndrome (Hamid et al. 2020). Besides respiratory illness, some patients also exhibited gastro-intestinal (GI) symptoms such as diarrhea, vomiting, nausea, loss of appetite, GI bleeding, and abdominal pain (Kopel et al. 2020). Recent, detection of SARS-CoV-2 virus in stools, suggested the possibility of fecal-oral transmission. This was later confirmed by the fact that SARS-CoV-2 can multiply in both respiratory and digestive tracts (Lamers et al. 2020). Furthermore, it was also reported that COVID-19 infection affects the anatomy and physiology of the gastro-intestinal tract thereby modulating gut microbiota for a long period (Dhar and Mohanty 2020). In addition, COVID-19 patients with GI symptoms did experience severe respiratory disorders than those without GI symptoms (Olaimat et al. 2020).

\section{Cross-talk between gut and lungs microbiome: an important aspect of respiratory diseases}

The term microbiome encompasses the entire microbial community such as bacteria, archaea, fungi, and viruses. Advances in research have led to the understanding that there is a dynamic cross-talk between the microbes of the gut- lung axis. This breakthrough quivered the ancient dogma of the sterile lung environment (Marsland et al. 2015). Linking of the gut and the lung niche is mediated through this axis as it is a route for the passage of hormones, microbial metabolites, cytokines, and endotoxins into the bloodstream. A balanced gut community is of vital importance in pulmonary immunity. Several studies suggest that dysbiosis in gut microbiota influence pulmonary dysfunction by modulating the immune responses of neutrophils (Enaud et al. 2020), T cell subsets (Ohnmacht 2016; Luu et al. 2017), inflammatory cytokines (Scales et al. 2016) Toll-like receptors (Wang et al. 2018) and many more. The local or distal immune modulation of the commensal microbes in the lungs and gut affects the onset of the infection process. However, the indigenous gut commensals confer colonization resistance from the microbial pathogens by the concept of 'barrier effect' and thus, aid in protecting the gut niche from being altered (George Kerry et al. 2018). The role of the gut microbiome and its effect on respiratory disease is summarized in Table 2.

During infection of the respiratory tract, the commensal organisms of our body stimulate the local (from lungs) and the adjacent distal immune response (at the sites of the gut) (Chang and Kao 2019). The gut-lung axis is assumed to be bidirectional, meaning infection by SARS-CoV-2 at the lungs trigger an immune response in the GI tract. The infection of the lungs with SARS-CoV-2 causes an epithelial disruption in the gas exchange areas and the associated airways (Fanos et al. 2020). Epithelial cells of the alveoli with angiotensin-converting enzyme 2 (ACE2) receptor serve as the binding site for SARS and SARSCoV-2. The concentration of pro-inflammatory cytokines [Interferon gamma-induced protein 10 (IP-10); monocyte chemoattractant protein 1 (MCP1) and Interleukin 8 (IL8)] (Sinha et al. 2020). Overproduction of cytokines and chemokines, activation of $\mathrm{T}$ helper cell-mediated immunity, and host inflammatory response was observed during the acute phase of SARS and SARS-CoV-2 infection (Qian et al. 2013). Recent studies suggest that the involvement of the gut in COVID-19 is even greater and more prolonged compared with the lung (Xu et al. 2020). Strikingly, it has been reported that probiotics show significant microbial inhibitory properties through alveolar macrophage, neutrophils, natural killer cells, and increased levels of

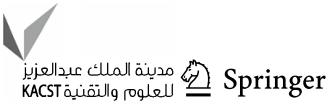




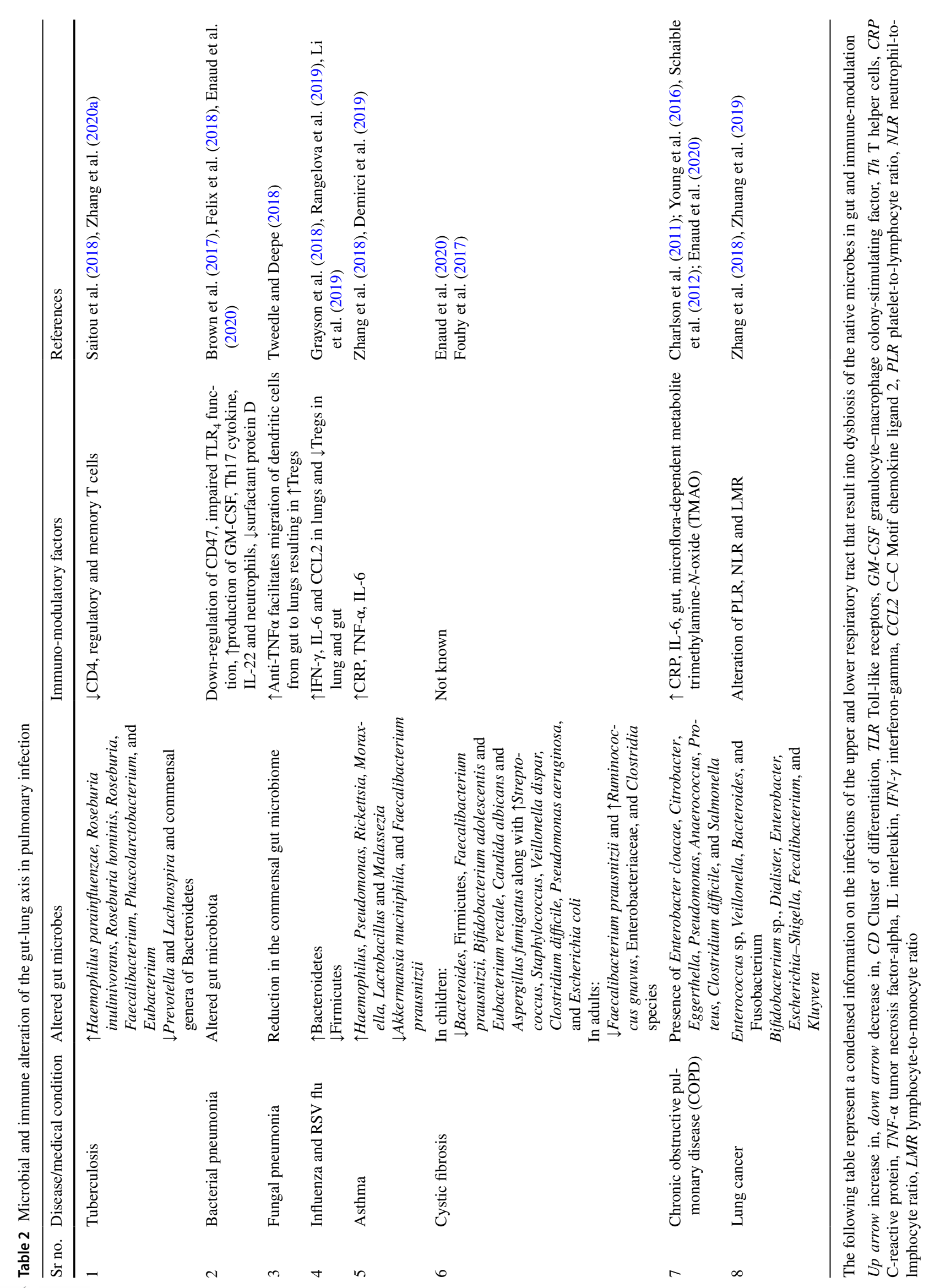


pro-inflammatory cytokines like TNF- $\alpha$ and IL-6 in the lung (Dumas et al. 2018). In addition, probiotic bacteria can bind the invading virus and inhibit the pathogen-host cell receptor interaction. Therefore, the use of probiotics as medication restricts respiratory viral infections by fortifying the mucosal immunity (Marsland et al. 2015).

\section{Immunomodulatory activities of probiotics}

Given the fundamental importance of gut microbiota in influencing lung diseases, the targeted manipulation of gut bacteria using certain dietary supplements, propose a promising therapeutic approach. Emerging studies suggest the use of probiotic bacteria in the treatment or prevention of a wide range of human diseases, medical conditions, and syndromes. Probiotics are live microorganisms that, when administered in adequate amounts, confer a health benefit to the host (FAO and WHO, UN). Probiotic mechanisms in preventive and therapeutic approaches consist of amending the intestinal microbial communities, immunomodulation, clamping down the pathogens, and protection of the intestinal barrier. They have already been used in the treatment of antibiotic-associated diarrhea, inflammatory bowel disease, and different chronic inflammatory diseases (Mortaz et al. 2013).

Immune system modulation is a key factor in the prevention of infectious diseases. Probiotic microbes have demonstrated their ability to stimulate and modulate the immune system and also to reduce inflammation (Hardy et al. 2013). Probiotics are known to decrease the severity of infections in the GI tract and the upper respiratory tract by acting on both the innate and the adaptive immune systems. Currently, the use of probiotic microorganisms and their metabolic products represents a promising approach for the treatment of viral diseases (Ryan et al. 2015). Colonization of intestinal epithelium by the probiotic bacteria has been shown to reduce the incidences and symptoms of viral respiratory infections. This is achieved by the upsurge of $\operatorname{IgA}$ expressing $\mathrm{B}$ cells in the colon and lymph nodes in conjunction with the increasing population of the $\mathrm{T}$ follicular helper cells and IL-23-expressing dendritic cells. Furthermore, probiotics also comprise of immunostimulatory constituents such as peptidoglycan, lipoteichoic acid, Toll-like receptor (TLR) ligands, and muramyl dipeptide, which accentuates their immunomodulatory potency (Kanauchi et al. 2018). The recent study of Ji et al., demonstrated that the supplementation of probiotics to RSV-infected mice has significantly elevated the abundance of short-chain fatty acid (SCFA) producing gut microbiota which in turn up-regulate the production of interferon $\beta$. Besides, they have also reported the upsurge of Corynebacterium and Lactobacillus species in the lung due to higher SCFA production, consequently leading to the activation of interferon $\beta$ production in alveolar macrophages (Ji et al. 2020). A randomized, double-blind and placebo-controlled human study of 109 adults demonstrated the enhanced level of anti-inflammatory cytokines IL-4 and IL-10 and reduced plasma peroxidation and oxidative stress upon administration of L. plantarum DR7.

The COVID-19 infection affects the lung tissues and gut, thus activating the inflammatory response. It increases the proinflammatory cytokines (IFN- $\gamma, \mathrm{TNF}-\alpha$ ) which lead to the emergence of the cytokine storm. This response is probably because of the activation of $\mathrm{T}$ helper cells $\left(\mathrm{T}_{\mathrm{h} 1}\right)$ cell response in the lung tissue (Lehtoranta et al. 2014). In the case of the human gut environment, dysbiosis in the gut microbiota results in the imbalance of $\mathrm{T}_{\mathrm{h} 1}$ and $\mathrm{T}_{\mathrm{h} 2}$ which further results in the activation of proinflammatory cytokine and eventually the cytokine storm in the lungs as well (Qian et al. 2017). Upon administration of probiotics, there is colonization of so-called "good bacteria" in the gut which leads to a shift in the balance between $\mathrm{T}_{\mathrm{h} 1 /} \mathrm{T}_{\mathrm{h} 2}$ cells that reduces the cytokine storm and reduces the severity of diseases (Qian et al. 2017). Recently it has been found that medication with probiotic bacteria using Bifidobacteria and Lactobacillus provides a significant chance of recovery against COVID-19 (Fanos et al. 2020). Previously, these probiotic bacteria Probiotics were reported to have beneficial effects against respiratory infection by the influenza virus (Zelaya et al. 2016). Administration and consumption of probiotics advance the immune system by enhancing the level of type I interferons, antigen-presenting cells (APC), Natural Killer cells (NK cells), and B and T cells of the lungs (Dhar and Mohanty 2020). Probiotic administration can also improve the pro- and anti-inflammatory cytokines, helping to clear the viral infection by minimizing the cell damage in the lungs (Baud et al. 2020).

\section{Role of probiotics in respiratory virus infections}

By maintaining the gut homeostasis probiotics are beneficial in preventing antibiotic-associated diarrhea, also prevent the adhesion and colonization of pathogenic microbes (Guo et al. 2019). Hence, protect from infections in the gastrointestinal tract and various other body sites. The respiratory tract is one of them. Several animal model studies have reported the beneficial effects of $L$. plantarum species that, reduce the symptoms of influenza viral infection and increases the body weight and survival rate of mice (Maeda et al. 2009; Kawashima et al. 2011; Park et al. 2013). Similarly, the anti-viral activity of $L$. case $i$ was reported by Hori et al. (2001) against the $\mathrm{H}_{1} \mathrm{~N}_{1}$ virus, they observed a reduction in viral titer (Hori et al. 2001). L. rhamnosus is reported for its ability to stimulate 
the host immune system and anti-influenza viral activity. With Lactobacillus species, Bifidobacterium species are also commensal bacterium of the human gut and reported for their beneficial effects to host. It promotes good digestion, boosts the immune system, and inhibits intestinal pathogens (Mayo and Sinderen 2010). In many studies, bifidobacterial strains were used in combination with lactic acid bacteria to assess their anti-vital potential. A double-blind, placebo-controlled, randomized trial of 201 healthy infants aged between 4 and 10 months was administered with a combination of $L$. reuteri DSM 1793 and $B$. animalis spp. Lactis BB12. The combination reduced the RTI symptoms, fever, and antibiotic consumption (Weizman et al. 2005), while a similar effect was also observed with only $B$. animalis spp. and Lactis BB12 strain (Taipale et al. 2011).

The use of L. plantarum, L. salivarius, L. rhamnosus GG, and $L$. case $i$ Shirota is well reported for their antiviral activity against rotavirus, transmissible gastroenteritis coronavirus (Maragkoudakis et al. 2010; Rejish Kumar et al. 2010). Furthermore, the in vitro antiviral activity of probiotic strain Enterococcus faecium NCIMB 10,415 demonstrated the $3-\log$ reduction in the viral titer. The authors also reported that the E. faecium alters the expression of interleukins, IL-6, and IL-8 and induces the production of Nitric oxide which might be the reason for its antiviral activity (Chai et al. 2012). The study of Wang et al. (2019) also reported the antiviral activity of Lactobacillus plantarum against transmissible gastroenteritis virus, which in turn activates the antiviral proteins via JAK-STAT signalling pathway and up-regulate the expression of interferon genes, resulting in anti-transmissible gastroenteritis virus activity (Wang et al.
2019). These reports further indicate the efficacy of probiotic strains to treat the infection of coronavirus.

Besides the oral intake of probiotics, the nasopharynx sprays have also shown promising results in terms of reduced viral infections (Lehtoranta et al. 2014). The topical application of probiotics has been proved effective against Chronic Rhinosinusitis (CRS) and asthma, redefining the futuristic research (Cervin 2018). The ability of probiotics to combat viral infections can be a solution to the lack of antiviral agents (Kassaa et al. 2015). Lactobacillus and Bifidobacterium genus are the most studied genus concerning anti-respiratory virus activity specifically against $\mathrm{H}_{1} \mathrm{~N}_{1}$, Influenza, and RSV viruses (Table 3).

All these studies found that the administration of probiotics shortens the duration of infections, reduces the severity, (de Vrese et al. 2006; Boge et al. 2009) improves immunity and gut health (Akatsu et al. 2013). Hence, we believe that these probiotics can be good neutraceutical and promising immunobiotic agents to treat the infection of COVID-19.

\section{Probiotic metabolites and antiviral activity}

Lactic acid bacteria (LAB) are known to produce a variety of antimicrobial substances such as acids, peptides or proteins, non-ribosomal peptides (NRP), hydrogen peroxide, and other metabolites. Hydrogen peroxide is toxic to many non-catalase microorganisms; however, their antirespiratory tract viral activity is not known but their activity against human immunodeficiency virus HIV-1 and Herpes simplex virus HSV-2 were reported earlier (Klebanoff and Coombs 1991; Conti et al. 2009). Lactic acid, the product

Table 3 Use of probiotics as antiviral supplements

\begin{tabular}{|c|c|c|c|c|c|}
\hline Sr. No & Probiotic strains & Origin & Anti-viral activity & $\begin{array}{l}\text { Mechanisms of immune modula- } \\
\text { tion }\end{array}$ & References \\
\hline 1 & Lactobacillus plantarum L-137 & Fermented food & Influenza virus $\mathrm{A}-\mathrm{H}_{1} \mathrm{~N}_{1}$ & $\begin{array}{l}\text { Proinflammatory activity } \\
\text { Th1 immune response }\end{array}$ & $\begin{array}{l}\text { Murosaki et al. (1998) } \\
\text { Maeda et al. (2009) }\end{array}$ \\
\hline 2 & L. plantarum DK 119 & Fermented food & Influenza virus A & Increase of IFN $\gamma$ and IL-2 & Park et al. (2013) \\
\hline 3 & L. rhamnosus CRL 1505 & - & RSV & $\begin{array}{l}\text { Innate immunity stimulation and } \\
\text { induction of IFN- } \alpha \text { produc- } \\
\text { tion via TLR3/RIG-I-triggered } \\
\text { antiviral respiratory immune } \\
\text { response }\end{array}$ & Tomosada et al. (2013) \\
\hline 4 & L. gasseri $\mathrm{TMC} 0356$ & Human gut & $\mathrm{H}_{1} \mathrm{~N}_{1}$ & $\begin{array}{l}\text { Decrease in the severity of } \\
\text { symptoms and viral titer. } \\
\text { Stimulation of IL-12, IL-6, } \\
\text { IFN } \gamma \text {, and IgA production }\end{array}$ & Kawase et al. (2010) \\
\hline 5 & Bifidobacterium longum BB536 & Healthy Infant & $\mathrm{H}_{1} \mathrm{~N}_{1}$ & Increase in IFN $\gamma$ and IL-6 & Iwabuchi et al. (2011) \\
\hline 6 & B. animalis ssp. Lactis BB12 & - & RTIs & Reduction in the viral titer & Taipale et al. (2011) \\
\hline
\end{tabular}

In this table, various probiotic strains reported to have anti-viral activity, along with the immune-modulatory mechanisms have been listed to understand their potential applications in prevention against SARS-CoV-2

(-) refer to the data unavailability

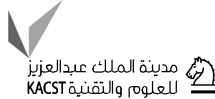


of carbohydrate metabolism is an important microbicidal compound, it kills acid-sensitive microbes. It helps the host cells in preventing viral replication (Conti et al. 2009). Furthermore, the study of Verma et al. 2019, demonstrated the expression and secretion of Human (Angiotensin-Converting Enzyme) ACE-2 (a receptor required by COVID-19 virus for its binding) in Lactobacillus paracasei (Verma et al. 2019). Binding of this secreted ACE-2 with COVID-19 binding protein can prevent its entry into the cell and thus reduced the chances of infection (Rizzo et al. 2020).

Antimicrobial peptides are produced by probiotics organisms are the molecules most characterized for their antimicrobial activity and anti-viral activity. Bacteriocins are the antimicrobial peptides produced by genera Lactobacillus and Enterococcus spp. having broad-spectrum activity against various Gram-positive and Gram-negative bacteria. It can be used as alternatives to antibiotics or in combination with antibiotics. Bacteriocin compounds such as staphylococcin 188, enterocin AAR-74, erwiniocin NA4 have been evaluated for antiviral activity. Their activity is reported against HIV, HSV, Coliphage, influenza virus, and particularly H1N1 virus (Klebanoff and Coombs 1991; Quereshi et al. 2006; Conti et al. 2009; Lange-Starke et al. 2014). Similarly, the nonribosomal peptides (NRPs) are also the secondary metabolites produced by probiotic microbes that have very broad clinical applications. Their uses are reported as antibiotics (daptomycin), anti-tumor drugs (bleomycin), antifungal drugs, and immunosuppressants (cyclosporin) (Walsh 2008).

\section{Conclusion}

There is no specific antiviral treatment or vaccine recommended for COVID-19. Oxygen therapy, non-invasive (NIV), and invasive mechanical ventilation (IMV) is used in cases with severe respiratory outcomes (Carter et al. 2020). To date, only one anti-viral drug-remdesivir, an RNA-dependent RNA-polymerase (RdRp) inhibitor of SARS-CoV-2 is used as the first drug for the treatment of COVID-19 patients (Beigel et al. 2020). However, with the increased mutation rate of SARS-CoV-2, the susceptibility of the virus to remdesivir drugs has been challenged. In addition, there are certain cases across 30 different countries associated with the failure of this antiviral agent (Martinot et al. 2020). Therefore, until the availability of specific treatment against COVID-19, prevention is the only measure. Different types of immunity-boosting foods such as fruits, vitamins, antioxidants, prebiotics, and probiotics are considered to have beneficiary effects on the host (Arshad et al. 2020; Olaimat et al. 2020). Probiotic bacteria are generally recognized as safe (GRAS) (Gerritsen et al. 2011). Upon administration, they benefit the host by ameliorating the gut health and immune system functioning. The probiotic strains and their metabolites such as bacteriocins have been studied as potential anti-viral agents. Hence, knowing the fact of the high mutational rate of RNA viruses and a major challenge of restricted antibiotic efficacy, we believe that the administration of probiotics will help in boosting the host-immunity, and similar to other anti-viral studies it might reduce the symptoms of the novel coronavirus. Consequently, in a view of prevention being better than cure, probiotics have become a neutraceutical and promising immunobiotic agents to possibly treat the infection of COVID-19 in the wake of the absence of a vaccine or proven therapeutic intervention.

Acknowledgements The authors are thankful to the director, CSIRNational Chemical Laboratory, Pune for providing infrastructure facilities. KG and RS are thankful to UGC and CSIR for fellowship support and the Academy of Scientific and Innovative Research (AcSIR), Ghaziabad, India for pursuing doctoral studies.

Author contributions $\mathrm{KG}, \mathrm{RS}$, and SD wrote the manuscript and researched literature. MD conceived the idea and reviewed the manuscript before submission.

\section{Compliance with ethical standards}

Conflict of interest The authors declare no competing interests.

\section{References}

Akatsu H, Iwabuchi N, Xiao J et al (2013) Clinical effects of probiotic Bifidobacterium longum BB536 on immune function and intestinal microbiota in elderly patients receiving enteral tube feeding. J Parenter Enter Nutr 37:631-640. https://doi.org/10.1177/01486 07112467819

Al Kassaa I, Hober D, Hamze M et al (2015) Vaginal Lactobacillus gasseri CMUL57 can inhibit herpes simplex type 2 but not Coxsackievirus B4E2. Arch Microbiol 197:657-664. https://doi. org/10.1007/s00203-015-1101-8

Arshad MS, Khan U, Sadiq A et al (2020) Coronavirus disease (COVID-19) and immunity booster green foods: a mini review. Food Sci Nutr 8:3971-3976. https://doi.org/10.1002/fsn3.1719

Baud D, Dimopoulou Agri V, Gibson GR et al (2020) Using probiotics to flatten the curve of coronavirus disease COVID-2019 pandemic. Front Public Health 8:186. https://doi.org/10.3389/ fpubh.2020.00186

Beigel JH, Tomashek KM, Dodd LE et al (2020) Remdesivir for the treatment of covid-19-preliminary report. N Engl J Med. https ://doi.org/10.1056/nejmoa2007764

Boge T, Rémigy M, Vaudaine S et al (2009) A probiotic fermented dairy drink improves antibody response to influenza vaccination in the elderly in two randomised controlled trials. Vaccine 27:5677-5684. https://doi.org/10.1016/j.vaccine.2009.06.094

Bottari B, Castellone V, Neviani E (2020) Probiotics and covid-19. Int J Food Sci Nutr. https://doi.org/10.1080/09637486.2020.1807475

Brown RL, Sequeira RP, Clarke TB (2017) The microbiota protects against respiratory infection via GM-CSF signaling. Nat Commun 8:1512. https://doi.org/10.1038/s41467-017-01803-x

Carter C, Aedy H, Notter J (2020) COVID-19 disease: non-invasive ventilation and high frequency nasal oxygenation. Clin Integr Care. https://doi.org/10.1016/j.intcar.2020.100006

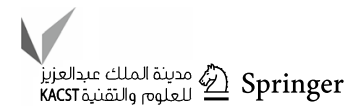


Cervin AU (2018) The potential for topical probiotic treatment of chronic rhinosinusitis, a personal perspective. Front Cell Infect Microbiol. https://doi.org/10.3389/fcimb.2017.00530

Chai W, Burwinkel M, Wang Z et al (2012) (2012) Antiviral effects of a probiotic Enterococcus faecium strain against transmissible gastroenteritis coronavirus. Arch Virol 1584(158):799-807. https ://doi.org/10.1007/S00705-012-1543-0

Chang CS, Kao CY (2019) Current understanding of the gut microbiota shaping mechanisms. J Biomed Sci 26:59

Charlson ES, Bittinger K, Haas AR et al (2011) Topographical continuity of bacterial populations in the healthy human respiratory tract. Am J Respir Crit Care Med 184:957-963. https://doi. org/10.1164/rccm.201104-0655OC

Coleman CM, Frieman MB (2014) Coronaviruses: important emerging human pathogens. J Virol 88:5209-5212. https://doi.org/10.1128/ jvi.03488-13

Conti C, Malacrino C, Mastromarino P (2009) Inhibition of herpes simplex virus type 2 by vaginal lactobacilli. J Physiol Pharmacol 60:19-26

de Vrese M, Winkler P, Rautenberg P et al (2006) Probiotic bacteria reduced duration and severity but not the incidence of common cold episodes in a double blind, randomized, controlled trial. Vaccine 24:6670-6674. https://doi.org/10.1016/j.vacci ne. 2006.05 .048

Demirci M, Tokman HB, Uysal HK et al (2019) Reduced Akkermansia muciniphila and Faecalibacterium prausnitzii levels in the gut microbiota of children with allergic asthma. Allergol Immunopathol (Madr) 47:365-371. https://doi.org/10.1016/j.aller .2018 .12 .009

Dhar D, Mohanty A (2020) Gut microbiota and Covid-19-possible link and implications. Virus Res 285:198018

Dumas A, Bernard L, Poquet Y et al (2018) The role of the lung microbiota and the gut-lung axis in respiratory infectious diseases. Cell Microbiol 20:e12966. https://doi.org/10.1111/cmi.12966

Enaud R, Prevel R, Ciarlo E et al (2020) The gut-lung axis in health and respiratory diseases: a place for inter-organ and inter-kingdom crosstalks. Front Cell Infect Microbiol 10:9

Fanos V, Pintus MC, Pintus R, Marcialis MA (2020) Lung microbiota in the acute respiratory disease: from coronavirus to metabolomics. J Pediatr Neonatal Individ Med 9:90139

Fehr AR, Channappanavar R, Perlman S (2017) Middle east respiratory syndrome: emergence of a pathogenic human coronavirus. Annu Rev Med 68:387-399. https://doi.org/10.1146/annurevmed-051215-031152

Felix KM, Jaimez IA, Nguyen TVV et al (2018) Gut microbiota contributes to resistance against Pneumococcal Pneumonia in immunodeficient Ragl mice. Front Cell Infect Microbiol 8:118. https ://doi.org/10.3389/fcimb.2018.00118

Fonkwo PN (2008) Pricing infectious disease. The economic and health implications of infectious diseases. EMBO Rep. https:// doi.org/10.1038/embor.2008.110

Fouhy F, Ronan NJ, O'Sullivan O et al (2017) A pilot study demonstrating the altered gut microbiota functionality in stable adults with cystic fibrosis. Sci Rep. https://doi.org/10.1038/s41598-01706880-y

Gao QY, Chen YX, Fang JY (2020) 2019 Novel coronavirus infection and gastrointestinal tract. J Dig Dis 21:125-126

George Kerry R, Patra JK, Gouda S et al (2018) Benefaction of probiotics for human health: a review. J Food Drug Anal 26:927-939

Gerritsen J, Smidt H, Rijkers GT, De Vos WM (2011) Intestinal microbiota in human health and disease: the impact of probiotics. Genes Nutr 6:209-240

Grayson MH, Camarda LE, Hussain SRA et al (2018) Intestinal microbiota disruption reduces regulatory $\mathrm{T}$ cells and increases respiratory viral infection mortality through increased IFN $\gamma$ production. Front Immunol. https://doi.org/10.3389/fimmu.2018.01587
Gu S, Chen Y, Wu Z et al (2020) Alterations of the gut microbiota in patients with COVID-19 or H1N1 influenza. Clin Infect Dis. https://doi.org/10.1093/cid/ciaa709

Guan W, Ni Z, Hu Y et al (2020) Clinical characteristics of coronavirus disease 2019 in China. N Engl J Med 382:1708-1720. https://doi.org/10.1056/NEJMoa2002032

Guo Q, Goldenberg JZ, Humphrey C et al (2019) Probiotics for the prevention of pediatric antibiotic-associated diarrhea. Cochrane Database Syst Rev. https://doi.org/10.1002/14651 858.CD004827.PUB5

Hamid S, Mir MY, Rohela GK (2020) Novel coronavirus disease (COVID-19): a pandemic (epidemiology, pathogenesis, and potential therapeutics). New Microbes New Infect. 35:100679. https://doi.org/10.1016/j.nmni.2020.100679

Hardy H, Harris J, Lyon E et al (2013) Probiotics, prebiotics and immunomodulation of gut mucosal defences: homeostasis and immunopathology. Nutrients 5:1869-1912. https://doi. org/10.3390/nu5061869

Hori T, Kiyoshima J, Shida K, Yasui H (2001) Effect of intranasal administration of Lactobacillus casei shirota on influenza virus infection of upper respiratory tract in mice. Clin Diagn Lab Immunol 8:593-597. https://doi.org/10.1128/ CDLI.8.3.593-597.2001

Iwabuchi N, Xiao J-Z, Yaeshima T, Iwatsuki K (2011) Oral administration of Bifidobacterium longum ameliorates influenza virus infection in mice. Biol Pharm Bull 34:1352-1355. https://doi. org/10.1248/bpb.34.1352

Ji J, Sun Q, Wang Q et al (2020) Probiotics confers protection against RSV infections by regulating gut and lung microbiotas to activate antiviral responses of alveolar macrophage. SSRN Electron J. https://doi.org/10.2139/ssrn.3471990

Jiang F, Deng L, Zhang L et al (2020) Review of the clinical characteristics of coronavirus disease 2019 (COVID-19). J Gen Intern Med 4:1-5

Kanauchi O, Andoh A, AbuBakar S, Yamamoto N (2018) Probiotics and paraprobiotics in viral infection: clinical application and effects on the innate and acquired immune systems. Curr Pharm Des 24:710. https://doi.org/10.2174/138161282466618 0116163411

Kawase M, He F, Kubota A et al (2010) Oral administration of lactobacilli from human intestinal tract protects mice against influenza virus infection. Lett Appl Microbiol 51:6-10. https://doi. org/10.1111/j.1472-765X.2010.02849.x

Kawashima T, Hayashi K, Kosaka A et al (2011) Lactobacillus plantarum strain YU from fermented foods activates Th1 and protective immune responses. Int Immunopharmacol 11:20172024. https://doi.org/10.1016/j.intimp.2011.08.013

Klebanoff SJ, Coombs RW (1991) Viricidal effect of Lactobacillus acidophilus on human immunodeficiency virus type 1: possible role in heterosexual transmission. J Exp Med 174:289-292. https://doi.org/10.1084/jem.174.1.289

Kopel J, Perisetti A, Gajendran M et al (2020) Clinical Insights into the gastrointestinal manifestations of COVID-19. Dig Dis Sci 65:1932-1939

Lamers MM, Beumer J, van der Vaart J et al (2020) SARS-CoV-2 productively infects human gut enterocytes. Science. https:// doi.org/10.1126/science.abc1669

Lange-Starke A, Petereit A, Truyen U et al (2014) Antiviral potential of selected starter cultures, bacteriocins and D, L-lactic acid. Food Environ Virol 6:42-47. https://doi.org/10.1007/s1256 0-013-9135-z

Lee T, Ahn JH, Park SY et al (2018) Recent advances in AIV biosensors composed of nanobio hybrid material. Micromachines 9:651

Lehtoranta L, Pitkäranta A, Korpela R (2014) Probiotics in respiratory virus infections. Eur J Clin Microbiol Infect Dis 33:1289-1302 
Li N, Ma WT, Pang M et al (2019) The commensal microbiota and viral infection: a comprehensive review. Front Immunol 10:1551

Li X, Geng M, Peng Y et al (2020) Molecular immune pathogenesis and diagnosis of COVID-19. J Pharm Anal. https://doi. org/10.1016/J.JPHA.2020.03.001

Luo G, Gao SJ (2020) Global health concerns stirred by emerging viral infections. J Med Virol 92:399-400. https://doi.org/10.1002/ jmv. 25683

Luu M, Steinhoff U, Visekruna A (2017) Functional heterogeneity of gut-resident regulatory T cells. Clin Transl Immunol 6:e156. https://doi.org/10.1038/cti.2017.39

Lysholm F, Wetterbom A, Lindau C et al (2012) Characterization of the viral microbiome in patients with severe lower respiratory tract infections, using metagenomic sequencing. PLoS ONE 7:e30875. https://doi.org/10.1371/journal.pone.0030875

Maeda N, Nakamura R, Hirose Y et al (2009) Oral administration of heat-killed Lactobacillus plantarum L-137 enhances protection against influenza virus infection by stimulation of type I interferon production in mice. Int Immunopharmacol 9:1122-1125. https://doi.org/10.1016/j.intimp.2009.04.015

Maragkoudakis PA, Chingwaru W, Gradisnik L et al (2010) Lactic acid bacteria efficiently protect human and animal intestinal epithelial and immune cells from enteric virus infection. Int J Food Microbiol. https://doi.org/10.1016/j.ijfoodmicro.2009.12.024

Marsland BJ, Aur A, Trompette A, Gollwitzer ES (2015) The Gut-Lung Axis In Respiratory Disease. Ann Am Thorac Soc 12:150-156. https://doi.org/10.1513/AnnalsATS.201503-133AW

Martinot M, Jary A, Fafi-Kremer S et al (2020) Remdesivir failure with SARS-CoV-2 RNA-dependent RNA-polymerase mutation in a B-cell immunodeficient patient with protracted Covid-19. Clin Infect Dis. https://doi.org/10.1093/cid/ciaa1474

Mayo B, Sinderen D (2010) Bifidobacteria: genomics and molecular aspects. Caister Academic, Norfolk, UK

Meo SA, Alhowikan AM, Khlaiwi TAL et al (2020) Novel coronavirus 2019-nCoV: prevalence, biological and clinical characteristics comparison with SARS-CoV and MERS-CoV. Eur Rev Med Pharmacol Sci 24:2012-2019

Mortaz E, Adcock IM, Folkerts G et al (2013) Probiotics in the management of lung diseases. Mediat Inflamm. https://doi. org/10.1155/2013/751068

Murosaki S, Yamamoto Y, Ito K et al (1998) Heat-killed Lactobacillus plantarum L-137 suppresses naturally fed antigen-specific IgE production by stimulation of IL-12 production in mice. $\mathrm{J}$ Allergy Clin Immunol 102:57-64. https://doi.org/10.1016/S0091 $-6749(98) 70055-7$

Ohnmacht C (2016) Microbiota, regulatory T cell subsets, and allergic disorders. Allergo J Int 25:114-123. https://doi.org/10.1007/ s40629-016-0118-0

Olaimat AN, Aolymat I, Al-Holy M et al (2020) The potential application of probiotics and prebiotics for the prevention and treatment of COVID-19. NPJ Sci Food 4:1-7. https://doi.org/10.1038/ s41538-020-00078-9

Park MK, Vu Kwon NGOYM et al (2013) Lactobacillus plantarum DK119 as a probiotic confers protection against influenza virus by modulating innate immunity. PLoS ONE. https://doi. org/10.1371/journal.pone.0075368

Park M, Thwaites RS, Openshaw PJM (2020) COVID-19: lessons from SARS and MERS. Eur J Immunol 50:308-311. https://doi. org/10.1002/eji.202070035

Pfeiffer JK, Virgin HW (2016) Transkingdom control of viral infection and immunity in the mammalian intestine. Science 351:aad5872. https://doi.org/10.1126/science.aad5872

Qian Z, Travanty EA, Oko L et al (2013) Innate immune response of human alveolar type II cells infected with severe acute respiratory syndrome-coronavirus. Am J Respir Cell Mol Biol 48:742748. https://doi.org/10.1165/rcmb.2012-0339OC
Qian W, Wei X, Guo K et al (2017) The C-terminal effector domain of non-structural protein 1 of influenza A virus blocks IFN- $\beta$ production by targeting TNF receptor-associated factor 3 . Front Immunol 8:779-779. https://doi.org/10.3389/fimmu.2017.00779

Quereshi H, Saeed S, Ahmed S, Rasool SA (2006) Coliphage has as a model for antiviral studies/spectrum by some indigenous bacteriocin like inhibitory substances (BLIS). Pak J Pharm Sci 19:182-185

Rangelova E, Wefer A, Persson S et al (2019) Surgery improves survival after neoadjuvant therapy for borderline and locally advanced pancreatic cancer. Ann Surg. https://doi.org/10.1097/ sla.0000000000003301

Rizzo P, Vieceli Dalla Sega F, Fortini F, Marracino L, Rapezzi C, Ferrari R (2020) COVID-19 in the heart and the lungs: could we "Notch" the inflammatory storm?. Basic Res Cardiol 115(3):31. https://doi.org/10.1007/s00395-020-0791-5

Rejish Kumar Seo Mun VJBJMR et al (2010) Putative probiotic Lactobacillus spp. from porcine gastrointestinal tract inhibit transmissible gastroenteritis coronavirus and enteric bacterial pathogens. Trop Anim Health Prod 42:1855-1860. https://doi.org/10.1007/ s11250-010-9648-5

Ryan PM, Ross RP, Fitzgerald GF et al (2015) Sugar-coated: exopolysaccharide producing lactic acid bacteria for food and human health applications. Food Funct 6:679-693. https://doi. org/10.1039/c4fo00529e

Sahadulla M (2018) Infections of the respiratory system. Concise handbook of infectious diseases. Jaypee Brothers Medical Publishers (P) Ltd., New Delhi, pp 65-65

Saitou M, Nemoto D, Utano K et al (2018) Identification of intestinal abnormalities in patients with active pulmonary tuberculosis using small bowel capsule endoscopy. Endosc Int Open 06:E1103-E1108. https://doi.org/10.1055/a-0655-2086

Scales BS, Dickson RP, Huffnagle GB (2016) A tale of two sites: how inflammation can reshape the microbiomes of the gut and lungs. J Leukoc Biol 100:943-950. https://doi.org/10.1189/jlb.3mr03 16-106r

Schaible B, Taylor CT, Schaffer K (2012) Hypoxia increases antibiotic resistance in Pseudomonas aeruginosa through altering the composition of multidrug efflux pumps. Antimicrob Agents Chemother 56:2114-2118. https://doi.org/10.1128/AAC.05574-11

Seo G, Lee G, Kim MJ et al (2020) Rapid Detection of COVID-19 causative virus (SARS-CoV-2) in human nasopharyngeal swab specimens using field-effect transistor-based biosensor. ACS Nano. https://doi.org/10.1021/acsnano.0c02823

Singhal T (2020) A review of coronavirus disease-2019 (COVID-19). Indian J Pediatr 87:281-286

Sinha P, Matthay MA, Calfee CS (2020) Is a "cytokine storm" relevant to COVID-19? JAMA Intern Med. https://doi.org/10.1001/jamai nternmed.2020.3313

Soriano JB, Kendrick PJ, Paulson KR et al (2020) Prevalence and attributable health burden of chronic respiratory diseases, 1990-2017: a systematic analysis for the Global Burden of Disease Study 2017. Lancet Respir Med 8:585-596. https://doi. org/10.1016/S2213-2600(20)30105-3

Su S, Wong G, Shi W et al (2016) Epidemiology, genetic recombination, and pathogenesis of coronaviruses. Trends Microbiol 24:490-502

Taipale T, Pienihkkinen K, Isolauri E et al (2011) Bifidobacterium animalis subsp. lactis BB-12 in reducing the risk of infections in infancy. Br J Nutr 105:409-416. https://doi.org/10.1017/S0007 114510003685

Tomosada Y, Chiba E, Zelaya H et al (2013) Nasally administered Lactobacillus rhamnosus strains differentially modulate respiratory antiviral immune responses and induce protection against respiratory syncytial virus infection. BMC Immunol 14:1-16. https://doi.org/10.1186/1471-2172-14-40

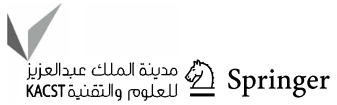


Tweedle JL, Deepe GS (2018) Tumor necrosis factor alpha antagonism reveals a gut/ lung axis that amplifies regulatory T cells in a pulmonary fungal infection. Infect Immun. https://doi.org/10.1128/ IAI.00109-18

Velavan TP, Meyer CG (2020) The COVID-19 epidemic. Trop Med Int Heal 25:278-280

Verma A, Xu K, Du T et al (2019) Expression of human ACE2 in lactobacillus and beneficial effects in diabetic retinopathy in mice. Mol Ther Methods Clin Dev 14:161-170. https://doi. org/10.1016/j.omtm.2019.06.007

Walsh CT (2008) The chemical versatility of natural-product assembly lines. Acc Chem Res 41:4-10. https://doi.org/10.1021/ar7000414

Wang H, Lian P, Niu X et al (2018) TLR4 deficiency reduces pulmonary resistance to Streptococcus pneumoniae in gut microbiota-disrupted mice. PLoS ONE. https://doi.org/10.1371/journ al.pone.0209183

Wang K, Ran L, Yan T et al (2019) Anti-TGEV miller strain infection effect of Lactobacillus plantarum supernatant based on the jAKSTAT1 signaling pathway. Front Microbiol 10:2540. https://doi. org/10.3389/FMICB.2019.02540

Weizman Z, Asli G, Alsheikh A (2005) Effect of a probiotic infant formula on infections in child care centers: comparison of two probiotic agents. Pediatrics 115:5-9. https://doi.org/10.1542/ peds.2004-1815

Wu Y, Guo C, Tang L et al (2020) Prolonged presence of SARS-CoV-2 viral RNA in faecal samples. Lancet Gastroenterol Hepatol 5:434-435

Xiao F, Tang M, Zheng X et al (2020) Evidence for gastrointestinal infection of SARS-CoV-2. Gastroenterology 158:1831-1833.e3. https://doi.org/10.1053/j.gastro.2020.02.055

Xu Z, Shi L, Wang Y et al (2020) Pathological findings of COVID19 associated with acute respiratory distress syndrome. Lancet Respir Med 8:420-422. https://doi.org/10.1016/S2213 $-2600(20) 30076-X$

Yeo C, Kaushal S, Yeo D (2020) Enteric involvement of coronaviruses: is faecal-oral transmission of SARS-CoV-2 possible? Lancet Gastroenterol Hepatol 5:335-337

Yi M (2020) Meeting of top scientists underway to slow coronavirus spread UN News. In: UN News. https://news.un.org/en/story /2020/02/1057161. Accessed 17 Oct 2020
Young RP, Hopkins RJ, Marsland B (2016) The gut-liver-lung axis: modulation of the innate immune response and its possible role in chronic obstructive pulmonary disease. Am J Respir Cell Mol Biol 54:161-169

Zelaya H, Alvarez S, Kitazawa H, Villena J (2016) Respiratory antiviral immunity and immunobiotics: beneficial effects on inflammation-coagulation interaction during influenza virus infection. Front Immunol 7:633

Zhai Y, Sun F, Li X et al (2005) Insights into SARS-CoV transcription and replication from the structure of the nsp7-nsp8 hexadecamer. Nat Struct Mol Biol 12:980-986. https://doi.org/10.1038/nsmb9 99

Zhang Y-Z, Holmes EC (2020) A genomic perspective on the origin and emergence of SARS-CoV-2. Cell. https://doi.org/10.1016/j. cell.2020.03.035

Zhang Y, Li T, Yuan H et al (2018) Correlations of inflammatory factors with intestinal flora and gastrointestinal incommensurate symptoms in children with Asthma. Med Sci Monit 24:79757979. https://doi.org/10.12659/MSM.910854

Zhang D, Li S, Wang N et al (2020) The cross-talk between gut microbiota and lungs in common lung diseases. Front Microbiol 11:301

Zhang S, Diao MY, Duan L et al (2020) The novel coronavirus (SARSCoV-2) infections in China: prevention, control and challenges. Intensive Care Med 46:591-593

Zhou P, Yang X-L, Wang X-G et al (2020) A pneumonia outbreak associated with a new coronavirus of probable bat origin. Nature 579:270-273. https://doi.org/10.1038/s41586-020-2012-7

Zhu Z, Lian X, Su X et al (2020) From SARS and MERS to COVID19: a brief summary and comparison of severe acute respiratory infections caused by three highly pathogenic human coronaviruses. Respir Res 21:224. https://doi.org/10.1186/s12931-02001479-w

Zhuang H, Cheng L, Wang Y et al (2019) Dysbiosis of the gut microbiome in lung cancer. Front Cell Infect Microbiol. https://doi. org/10.3389/fcimb.2019.00112

Zolnikova O, Komkova I, Potskherashvili N et al (2018) Application of probiotics for acute respiratory tract infections. Ital J Med 12:32-38 